\title{
ANÁLISE DE SÉRIES TEMPORAIS DE MULTICAMINHO EM ESTAÇÕES DE MONITORAMENTO CONTÍNUO
}

\author{
Multipaph Temporal Analysis Series in Continuous Monitoring Stations
}

\author{
DANIELE BARROCA MARRA ALVES ${ }^{1}$ \\ ENIUCE MENEZES DE SOUZA ${ }^{2}$ \\ VICTOR YUDI KANESHIRO ${ }^{1}$ \\ JÉSSICA SALDANHA SOUZA ${ }^{1}$
}

${ }^{1}$ Programa de Pós-Graduação em Ciências Cartográficas

Departamento de Cartografia - Faculdade de Ciências e Tecnologia/Universidade

Estadual Paulista - FCT/Unesp.

${ }^{2} \mathrm{UEM}^{-}$- Universidade Estadual de Maringá

Av. Colombro, 5790 - Campus Universitário, Bloco J12

87020-900 - Maringá - Paraná - Brasil

danibarroca@fct.unesp.br, eniuce@yahoo.com.br, vkaneshiro@hotmail.com, jessicasaldanha.souza@hotmail.com

\section{RESUMO}

Dados de estações de referência são muito empregados no posicionamento GNSS (Gobal Navigation Satellite System). Os dados dessas estações podem ser utilizados no posicionamento relativo ou no conceito de posicionamento baseado em redes. Erros nos sinais coletados nessas estações irão influenciar diretamente a acurácia do posicionamento. Nesse artigo, o objetivo é avaliar a qualidade desses dados através de séries temporais dos índices MP1 e MP2 de multicaminho. Foi realizado um estudo estatístico de séries temporais com 7 anos de observações diárias de 7 estações da RBMC (Rede Brasileira de Monitoramento Contínuo). Foi empregada modelagem harmônica, correlogramas e periodogramas de Fourier para avaliar tendência e uma possível sazonalidade das séries. Também foi utilizado um ajuste harmônico para identificar possíveis picos que ocorrem sazonalmente nas séries temporais. Finalizando, foram apontadas as possíveis causas da sazonalidade encontrada na maior parte das estações, onde foi possível notar picos dos valores de MP nos meses de março e outubro (principalmente nas estações localizadas na região do equador geomagnético).

Palavras-chave: Multicaminho; Séries Temporais; Sazonalidade. 


\section{ABSTRACT}

Data from reference stations are widely used in GNSS (Global Navigation Satellite System) positioning, and can be used in relative positioning or network-based positioning concept. Positioning accuracy will be directly influenced by errors in signals collected in these stations. In this paper, it is aimed at evaluating these data quality using temporal series of multipath index MP1 and MP2. A statistical study of temporal series with 7 years of daily observations related to 7 stations from RBMC (Rede Brasileira de Monitoramento Contínuo) was accomplished. In order to investigate trends and seasonality a linear regression model, correlograms, and Fourier periodograms were used. We also used a harmonic adjust to identify peaks on temporal series. At last, the possible causes of seasonality found in some stations were discussed. It was also possible to identify peaks in MP values of March and October months (mainly in stations located near geomagnetic equator).

Keywords: Multipath; Temporal Series; Seasonality.

\section{INTRODUÇÃO}

O GNSS (Global Navigation Satellite System) é uma tecnologia espacial que vem sendo amplamente empregada pela comunidade. Possui usuários das mais diversas áreas, tanto para fins científicos como comerciais ou civis. Esse crescimento expressivo vem impulsionando melhorias nos sistemas já existentes e o surgimento e efetivação de novos sistemas.

Dentre os sistemas que integram o GNSS, o GPS (Global Navigation Satellite System) (www.gps.gov), americano, com sua consolidada maturidade, é um dos mais conhecidos e empregados. Além do GPS, hoje o GLONASS (Global'naya Navigatsionnaya Sputnikovaya Sistema), russo, também se encontra operacional (http://www.glonass-ianc.rsa.ru/en/GLONASS/). Mas, diferentemente do GPS, que sempre possui 31 satélites operacionais, o GLONASS, apesar de possuir 29 satélites na constelação, mantém de 22-24 satélites operacionais (23 satélites operacionais em consulta realizada dia 27/02/13).

Considerando as constelações de satélites MEO (Medium Earth Orbit) que integram o GNSS, também deve-se citar as iniciativas da Europa e China, os sistemas GALILEO (http://www.esa.int/Our_Activities/Navigation/) e Beidou (http://www.beidou.gov.cn/), respectivamente. Ambos os sistemas devem estar com as constelações completas em 2020. Hoje (março 2013) 4 satélites GALILEO e 5 BEIDOU estão em órbita.

Os dados transmitidos pelos sistemas GNSS estão sujeitos a erros, tanto devido aos próprios satélites que compõem as constelações, como a propagação do sinal, receptor e à estação. A maior parte desses erros pode ser eliminada, reduzida ou modelada, isso depende muito do método de posicionamento empregado e da própria acurácia almejada. Um dos métodos de posicionamento mais utilizados é o posicionamento relativo. Através desse método a maior parte dos erros é minimizada, principalmente para linhas de base curtas. Mas, algo que permanece é o 
efeito do multicaminho (SOUZA, 2008). O multicaminho (seção 3) é de difícil modelagem, pois depende das condições físicas específicas de cada local, por isso, o que se tenta é realizar a coleta de dados evitando tal efeito, o que nem sempre é possível.

Quando são utilizados dados de redes de estações de referência (seção 2) como base no posicionamento relativo, o que se espera é que esse efeito seja mínimo, pois essas estações estão, teoricamente, bem localizadas. Algo que também é considerado como pré-requisito no posicionamento baseado em redes (ALVES, 2008; ALVES e MONICO, 2012). Caso exista a presença do multicaminho na estação de referência, esse erro irá afetar diretamente o posicionamento do usuário, pois tanto no relativo como no posicionamento em redes ele geralmente não é tratado, considera-se inexistente. Portanto, nesse artigo, o objetivo é avaliar através de séries temporais dos índices MP1 e MP2 (fornecem informações da qualidade dos dados) a existência e magnitude do multicaminho em estações de referência. Além disso, verificar quais eventos podem influenciar nos valores obtidos por esses índices e investigar estatisticamente a presença de sazonalidade e tendência nas séries. Nessa etapa, correlogramas, periodoramas e análise harmônica de Fourier foram aplicadas para modelar as séries temporais e detectar periodicidades. Os índices de MP1 e MP2 são brevemente descritos na seção 3. A metodologia é apresentada na seção 4 e os resultados obtidos na seção 5. As considerações finais são discutidas na seção 6 .

\section{REDES DE ESTAÇÕES DE REFERÊNCIA}

As redes de estações de referência são uma realidade em muitos países e é cada vez maior o número de redes ou a densificação das redes já existentes. Principalmente nos países mais desenvolvidos, como é o caso, por exemplo, da Alemanha, Canadá, Estados Unidos, Japão, etc, as redes de estações de referência são altamente densificadas. No que concerne ao Brasil, a RBMC (Rede Brasileira de Monitoramento Contínuo) (FORTES, 1997) (http://www.ibge.gov.br/home/ geociencias/geodesia/rbmc/rbmc.shtm?c=7) foi integrada com a RIBAC (Rede INCRA de Bases Comunitárias GNSS) (http://ribac.incra.gov.br/). Atualmente conta com pouco mais de 80 estações. No Estado de São Paulo, uma rede de estações GNSS ativas (denominada rede GNSS/SP) (www.gege.fct.unesp.br) apresenta uma densidade maior do que as demais regiões do país. Além disso, a maior parte das estações da rede GNSS/SP já foi homologada pelo IBGE e estão sendo integradas a RBMC.

As estações da RBMC e da rede GNSS/SP são materializadas através de pinos de centragem forçada, especialmente projetados, e cravados em pilares estáveis. Além dos receptores de dupla frequência, várias estações são dotadas de antenas do tipo choke-ring, cujo objetivo é reduzir multicaminho (SEEBER, 2003). Mas, teoricamente, a ideia é que estas estações sejam monumentadas em locais com boa visibilidade, já para tentar evitar tal efeito. 


\section{MULTICAMINHO}

O multicaminho ocorre, pois além do sinal que chega diretamente a antena, o receptor pode receber sinais refletidos em superfícies vizinhas à mesma, tais como construções, carros, árvores, massa d'água, cercas e etc. Além disso, reflexões também podem ocorrer no próprio satélite, mas é menos frequente. Quando ocorre multicaminho, o sinal chega ao receptor por dois caminhos diferentes: um direto e um indireto. Assim, os sinais recebidos no receptor podem ser composições do sinal direto com indiretos e apresentar distorções na fase da onda portadora e na modulação sobre ela (SOUZA, 2008; LEICK, 1995).

De acordo com Leick (1995) na observável fase o erro máximo pode chegar a aproximadamente um quarto do comprimento de onda, ou seja, $4,8 \mathrm{~cm}$ para a portadora L1. Já na pseudodistância a magnitude é maior, chegando na ordem dos metros.

A modelagem do multicaminho é bastante complicada, pois tal efeito depende de diversos fatores, tais como: ângulo de elevação do satélite, refratividade do meio onde se posiciona a antena, características da antena, objeto refletor e técnicas utilizadas nos receptores para reduzir os sinais refletidos. Existem algumas possibilidades de atenuação como, por exemplo, o uso de antenas especiais do tipo chocke ring ou tecnologia pinwheel, e até mesmo métodos de processamento no receptor ou dados (SOUZA, 2008). Mas, ainda a melhor maneira seria tentar evitar tal efeito.

Após coletados os dados, existem alguns fatores que funcionam como indicativos de multicaminho. Assim, pode-se avaliar a possível presença de tal efeito nos dados. Um desses indicativos é a repetibilidade ${ }^{1}$ em dias consecutivos. Para estações em repouso (como no caso das estações de monitoramento contínuo), onde as características físicas do meio permanecem inalteradas, o multicaminho em dias consecutivos também deve permanecer inalterado, o que o torna de fácil detecção. Já para estações em movimento a repetibilidade do efeito não deve ocorrer. Outro indicativo da ocorrência de multicaminho é o MP1 e MP2, detalhes na seção 3.1 .

\section{1. Índices de Multicaminho}

Os indicadores mais empregados para se avaliar o nível do multicaminho em estações GNSS são o MP1 e MP2. Esses índices podem ser obtidos através do software TEQC (UNAVCO, 2010). Para obter a formulação matemática do MP1 e MP2, é realizada uma subtração entre as observáveis de fase e pseudodistância. Com isso, a menos dos resíduos, os termos referentes aos relógios, troposfera e órbita são eliminados, sobrando apenas os termos de ambiguidade, multicaminho e ionosfera. Posteriormente são realizadas simplificações e os índices são obtidos,

\footnotetext{
${ }^{1}$ Como o efeito do multicaminho depende da geometria dos satélites e do ambiente físico que a antena está inserida (inclusive do tipo da antena), o efeito permanece praticamente o mesmo depois de um dia sideral em condições atmosféricas similares.
}

Bol. Ciênc. Geod., sec. Artigos, Curitiba, v. 19, nº 3, p.353-373, jul-set, 2013. 
como apresentados nas equações (1) e (2). Para mais detalhes consulte Estey e Meertens (1999) e Fortes (1997).

$$
\begin{aligned}
M P 1 & =P D_{L 1}-\left(1+\frac{2}{\alpha-1}\right) \phi_{L 1}+\left(\frac{2}{\alpha-1}\right) \phi_{L 2} \\
& =M_{P D 1}+B 1-\left(1+\frac{2}{\alpha-1}\right) M_{\phi 1}+\left(\frac{2}{\alpha-1}\right) M_{\phi 2}, \\
M P 2 & =P D_{L 2}-\left(\frac{2 \alpha}{\alpha-1}\right) \phi_{L 1}+\left(\frac{2 \alpha}{\alpha-1}-1\right) \phi_{L 2} \\
& =M_{P D 2}+B 2-\left(\frac{2 \alpha}{\alpha-1}\right) M_{\phi 1}+\left(\frac{2 \alpha}{\alpha-1}-1\right) M_{\phi 2},
\end{aligned}
$$

sendo que as tendências (bias terms) $B 1$ e $B 2$ resultantes das ambiguidades são dados por:

$$
\begin{aligned}
& B 1=-\left(1+\frac{2}{\alpha-1}\right) n_{1} \lambda_{1}+\left(\frac{2}{\alpha-1}\right) n_{2} \lambda_{2}, \\
& B 2=-\left(\frac{2 \alpha}{\alpha-1}\right) n_{1} \lambda_{1}+\left(\frac{2 \alpha}{\alpha-1}-1\right) n_{2} \lambda_{2},
\end{aligned}
$$

de forma que:

- $P D_{L 1}$ e $P D_{L 2}$ são as medidas simultâneas da pseudodistância nas portadoras L1 e

L2;

- $\alpha=\left(f_{L 1}^{2} / f_{L 2}^{2}\right)$, sendo $f_{L 1}$ e $f_{L 2}$ as frequências em L1 e L2 respectivamente;

- $\phi_{L 1}$ e $\phi_{L 2}$ são as medidas de fase para as portadoras L1 e L2;

- $M_{P D 1}$ e $M_{P D 2}$ representam o efeito do multicaminho em $P D_{L 1}$ e $P D_{L 2}$;

- $M_{\phi 1}$ e $M_{\phi 2}$ representam o efeito do multicaminho em $\phi_{L 1}$ e $\phi_{L 2}$;

- $\lambda_{1}$ e $\lambda_{2}$ são os comprimentos de onda para L1 e L2.

Observando as equações (1) e (2) nota-se no segundo membro das mesmas que os MPs podem ser calculados exclusivamente das observações de pseudodistância e fase. Portanto, é possível obter esses valores empregando apenas um receptor geodésico de dupla frequência. Por outro lado, analisando o terceiro membro dessas equações, verifica-se que o MP depende do efeito do multicaminho na pseudodistância $\left(M_{P D}\right)$ e fase $\left(M_{\phi}\right)$ e das tendências $B$ originadas das ambigüidades (desconhecidas) da fase. Portanto, independentemente do valor absoluto calculado para MP1 e MP2, o acompanhamento de sua variação ao longo do tempo fornece informações implícitas sobre a qualidade dos dados. Por exemplo, se um valor do MP1 muda bruscamente, isso significa que houve um efeito acentuado de multicaminho em $P D_{L 1}$ (dado por $M_{P D I}$ ) ou ocorreu uma perda de ciclos que provocou uma variação acentuada em B1 (descartando, neste caso, os efeitos das 
modificações em $M_{\phi 1}$ ou $M_{\phi 2}$, pois os valores do efeito do multicaminho na fase são muito menores que os relativos às pseudodistâncias) (FORTES, 1997; SOUZA, 2008). Em se tratando de estações de referência, como é o caso desse artigo, uma das principais causas das perdas de ciclo é a ionosfera, mais caracterizada pela cintilação ionosférica ${ }^{2}$.

Algo que deve ficar claro é que mesmo considerando estações de referência com mínima presença de objetos refletores, os índices MP1 e MP2 nunca serão nulos. De acordo com Hilla e Cline (2002) permanecem os efeitos do ruído do multicaminho $(<25 \mathrm{~cm})$, multicaminho da fase $(<7 \mathrm{~cm})$ e o ruído do multicaminho da fase $(<2 \mathrm{~mm})$. Mas esses efeitos são menores se comparados ao multicaminho na pseudodistância.

\section{SÉRIES TEMPORAIS}

Considerando que os índices MP1 e MP2 são gerados diariamente, tem-se, portanto, séries temporais que totalizam 365 observações por ano. Embora a repetibilidade diária, bem como as variações ao longo do dia, não possam ser verificadas nesses índices, são muito úteis para investigar comportamentos que se repetem com periodicidades maiores, tais como, meses e anos.

Um fator muito importante em séries temporais é a correlação entre as observações, o que impede que muitas técnicas que requerem independência não possam ser utilizadas para esses dados. Por outro lado, o maior intuito é entender tais correlações para investigar o processo gerador da série e determinar suas propriedades. Tendências, sazonalidades, dentre outros efeitos, tem influência direta na dependência das observações.

A tendência se refere à mudança no nível médio da série ao longo do tempo (CHATFIELD, 1995). A maioria das séries temporais exibe tendência de crescimento ou de decrescimento, ou seja, uma inclinação positiva ou negativa em relação ao eixo $x$ do gráfico temporal.

Por outro lado, pode-se observar nas séries temporais padrões que se repetem a cada $s$ períodos de tempo. Isto caracteriza a presença de sazonalidade, que por sua vez, pode ser aditiva, quando as flutuações sazonais são constantes não importando o nível médio da série, ou multiplicativa, quando o tamanho das flutuações sazonais varia dependendo do nível global da série.

Devido à quantidade de efeitos que podem estar sobrepostos na série temporal, muitas vezes não é possível identificar todos em uma simples representação gráfica. O coeficiente de autocorrelação entre as observações ao longo do tempo é uma medida muito útil (CHATFIELD, 1995). Dadas $n$ observações de uma série

\footnotetext{
${ }^{2}$ As cintilações ionosféricas são mudanças rápidas que ocorrem na fase e amplitude do sinal recebido, as quais são causadas por irregularidades na densidade de elétrons ao longo do caminho percorrido pelo sinal na ionosfera, podendo enfraquecer o sinal recebido pelos receptores GNSS, fazendo que ocorra em muitos casos a degradação ou até mesmo perca do sinal (CONKER et al., 2003).
}

Bol. Ciênc. Geod., sec. Artigos, Curitiba, v. 19, no 3, p.353-373, jul-set, 2013. 
temporal, $x_{1}, \ldots, x_{n}$, podemos formar pares $\left(x_{1}, x_{2}\right), \ldots,\left(x_{n-1}, x_{n}\right)$, e o coeficiente de correlação entre eles é dado por

$$
r_{1}=\frac{\sum_{t=1}^{n-1}\left(x_{t}-\bar{x}_{1}\right)\left(x_{t+1}-\bar{x}_{2}\right)}{\sqrt{\sum_{t=1}^{n-1}\left(x_{t}-\bar{x}_{1}\right)^{2} \sum_{t=1}^{n-1}\left(x_{t+1}-\bar{x}_{2}\right)^{2}}}
$$

com as médias amostrais

$$
\bar{x}_{1}=\sum_{t=1}^{n-1} \frac{x_{t}}{(n-1)} \text { e } \bar{x}_{2}=\sum_{t=2}^{n} \frac{x_{t}}{(n-1)}
$$

ou seja, para calcular as correlações de observações de $k$ períodos de tempo utilizase:

$$
r_{k}=\frac{\sum_{t=1}^{n-1}\left(x_{t}-\bar{x}\right)\left(x_{t+k}-\bar{x}\right)}{\sqrt{\sum_{t=1}^{n}\left(x_{t}-\bar{x}\right)^{2}}}
$$

em que

$$
\bar{x}=\sum_{t=1}^{n} \frac{x_{t}}{n}
$$

já que $\bar{x}_{1} \approx \bar{x}_{2}$, e assumindo variância constante. de -1 a 1 .

Assim como o coeficiente de correlação usual, as autocorrelações variam

O gráfico com os $k$ primeiros coeficientes de autocorrelação é chamado de correlograma (CHATFIELD, 1995). A correta análise do correlograma pode revelar as características de uma série temporal, seguindo as seguintes considerações:

- Em séries aleatórias os valores defasados são não correlacionados, portanto os valores de $r_{k} \approx 0$, para $k=1,2, \ldots, n$;

- Séries com correlação de curto prazo apresentam valor relativamente grande para $r_{1}$ seguido de valores que tendem a ficar sucessivamente menores;

- Valores de $r_{k}$ alternando entre positivo e negativo caracterizam uma série com correlação negativa;

- Séries com tendência podem ser identificadas por valores de $r_{k}$ que decaem lentamente para zero;

- Séries com sazonalidade podem ser identificadas quando o correlograma apresenta oscilações sazonais, como por exemplo, valores grandes (fora do intervalo de confiança de 95\%) para $r_{6}$ e $r_{12}$.

A análise do correlograma só faz sentido para séries estacionárias. Pode-se considerar uma série estacionária se sua média é constante e se a função de autocorrelação (autocovariância) depende apenas da defasagem na própria série, mas não do tempo. Logo, séries com tendência precisam ser transformadas antes de 
serem analisadas pelo correlograma. Embora o correlograma seja muito útil, sua correta interpretação é uma das tarefas mais difíceis em séries temporais (CHATFIELD, 1995). Nesse sentido, principalmente no caso de investigação de periodicidades, a análise harmônica de Fourier, bem como seu periodograma podem ser muito úteis.

\subsection{Análise harmônica}

A análise harmônica ou espectral é conhecida historicamente por permitir investigar periodicidades “escondidas” nas séries temporais. Em modelos usuais de regressão da forma

$$
Y_{t}=\mu_{t}+X_{t}
$$

em que $\mu_{t}$ é uma função determinística e $X_{t}$ uma variação não observada em torno de $\mu$ com média zero para todo $t$ (CRYER, 2008), sazonalidades ou efeitos cíclicos podem ser incorporados via funções cosseno:

$$
\mu_{t}=\beta \cos (2 \pi \omega t+\Phi)
$$

com $\beta>0$ sendo a amplitude, $\omega$ a frequência e $\Phi$ a fase da curva. Conforme $t$ varia, a curva oscila entre o máximo $\beta$ e o mínimo - $\beta$. Desde que a curva se repete exatamente a cada $1 / \omega$ unidades de tempo, $1 / \omega$ é chamada de período da curva cosseno. Entretanto, a equação (10) não é conveniente devido a não linearidade nos parâmetros $\beta$ e $\Phi$. Faz-se, portanto, conveniente usar a reparametrização:

$$
\beta \cos (2 \pi \omega t+\Phi)=\alpha_{1} \cos (2 \pi \omega t)+\beta_{1} \operatorname{sen}(2 \pi \omega t)
$$

em que $\beta=\sqrt{\alpha_{1}^{2}+\beta_{1}^{2}}, \Phi=a \tan \left(-\beta_{1} / \alpha_{1}\right), \alpha_{1}=\beta \cos (\Phi)$ e $\beta_{1}=-\beta \operatorname{sen}(\Phi)$.

Então, para uma frequência fixa $\omega$, pode-se usar $\cos (2 \pi \omega t)$ e $\operatorname{sen}(2 \pi \omega t)$ como variáveis preditoras e ajustar os $\alpha_{j}$ e $\beta_{j}$ por mínimos quadrados (MMQ). O modelo pode ser, portanto, expresso por:

$$
\mu_{t}=\beta_{0}+\alpha_{1} \cos (2 \pi \omega t)+\beta_{1} \operatorname{sen}(2 \pi \omega t)
$$

em que o termo constante $\beta_{0}$, pode ser interpretado como um cosseno com frequência zero.

A combinação linear geral de $m$ curvas cosseno com amplitudes, frequências e fases arbitrárias pode ser escrito por:

Bol. Ciênc. Geod., sec. Artigos, Curitiba, v. 19, nº 3, p.353-373, jul-set, 2013. 


$$
Y_{t}=\beta_{0}+\sum_{j=1}^{m} \alpha_{j} \cos \left(2 \pi \omega_{j} t\right)+\beta_{j} \operatorname{sen}\left(2 \pi \omega_{j} t\right)
$$

Embora os $\alpha_{j}$ e $\beta_{j}$ possam ser estimados pelo MMQ, para algumas frequências, o procedimento é simplificado. Se $n$ é impar, pode ser escrito como $n=2 k+1$ e as variáveis preditoras sem e cosseno em frequências $\frac{1}{n}, \frac{2}{n}, \ldots, \frac{k}{n}\left(=\frac{1}{2}-\frac{1}{2 n}\right)$, além de $\omega=0$, são ortogonais. Tais frequências são chamadas frequências de Fourier e

$$
\hat{\beta}_{0}=\bar{Y}, \hat{\alpha}_{j}=\frac{2}{n} \sum_{t=1}^{n} Y_{t} \cos \left(\frac{2 \pi \omega j t}{n}\right) \text { e } \hat{\beta}_{j}=\frac{2}{n} \sum_{t=1}^{n} Y_{t} \operatorname{sen}\left(\frac{2 \pi \omega j t}{n}\right)
$$

Se $n$ é par, $n=2 k$ as equações em (14) ainda são válidas para $j=1,2, \ldots, k-1$ e $\omega_{k}=k / n=1 / 2$.

Além disso, é possível mostrar que a contribuição do harmônico $\beta$ em (7) é dada por $n \beta^{2} / 2$, que se trata do conhecido periodograma de Fourier (CHATFIELD, 1995; CRYER, 2008). Portanto,

$$
I\left(\frac{j}{n}\right)=\frac{n\left(\hat{\alpha}_{1}^{2}+\hat{\beta}_{1}^{2}\right)}{2}
$$

para $j=1, \ldots, k$ se $n$ é par e $j=1, \ldots, k-1$ se ímpar.

Portanto, a ideia de localizar frequências ou periodicidades escondidas na série temporal vem da repetição da análise em (11) para todas as frequências $\frac{1}{n}, \frac{2}{n}, \ldots, \frac{k}{n}$, correlacionando-as com a série para uma medida de intensidade. Em outras palavras, quantifica a importância de cada frequência para a série em questão. Ajustando um modelo para todas as freqüências de Fourier, tem-se a conhecida análise harmônica. Se a série pode ser considerada determinística com periodicidade $S$, então o modelo harmônico na equação (13) pode ser ajustado para $j=1, . ., S / 2$ (MORETTIN e TOLOI, 2004).

\section{MÉTODOS E RESULTADOS}

Para o desenvolvimento dessa pesquisa foram escolhidas estações de monitoramento contínuo da RBMC. Na Figura 1 os círculos vermelhos representam as estações selecionadas para realizar as análises: BRAZ, POAL, POLI, PPTE, 
RECF, UBER e VICO. Essa escolha foi realizada baseada na quantidade de dados disponíveis (pelo menos seis anos de dados) e na localização geográfica. Note que foi selecionada uma estação no sul e outra no nordeste do país, as demais se concentram na região próxima ao equador geomagnético, principalmente PPTE, POLI, UBER e VICO.

Figura 01 - Estações da RBMC selecionadas para realizar os experimentos.

Fonte: http://ibge.gov.br/home/geociencias/geodesia/rbmc/rbmc.shtm?c=7 (abril/2013).

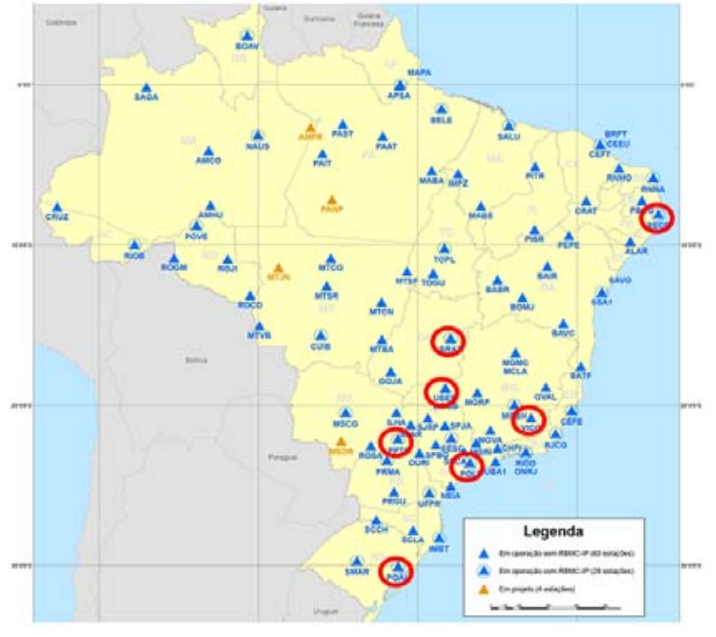

O software TEQC foi utilizado para obter os índices de MP1 e MP2 diários das estações selecionadas, com dados de 2006 a 2012. Posteriormente, com o software R (R CORE TEAM, 2012) foram geradas as séries temporais dos MPs e as análises estatísticas.

\subsection{Séries Temporais}

A Figura 2 apresenta as séries temporais de MP1 e MP2 para as sete estações. Para facilitar as análises foram utilizadas linhas verticais para representar troca de antena (A), troca de receptor (R), troca de antena e receptor (A+R) e atualização de firmware (F). Pois de acordo Ray (2006), as variações do MP podem estar correlacionadas com as mudanças no hardware da estação de rastreio.

Analisando a Figura 02 é nítida como a troca antena e receptor pode interferir no nível de ruídos dos dados. A estação BRAZ é um exemplo típico desse comportamento. Na Figura 03 é apresentada a série temporal dessa estação apenas para o ano de 2012. Os valores de MP1 e MP2 estavam estáveis até o dia 262 de 2012, momento onde ocorreu uma troca de antena e receptor. Após essa troca os valores aumentaram e permaneceram instáveis. Mas, devido a um raio que atingiu esse conjunto, ele teve que ter trocado e no dia 332 de 2012 o par antena/receptor 
anterior voltou a ser colocado no mesmo local. Note que a partir desse momento os valores de MP1 e MP2 voltaram a ter o mesmo comportamento anterior, ou seja, estáveis no decorrer do tempo.

Figura 02 - Séries temporais de MP1(a) e MP2 (b) de 7 estações da RBMC de 2006 a 2012 com suas respectivas trocas de antenas (A), receptores (R) e atualização de firmware (A).
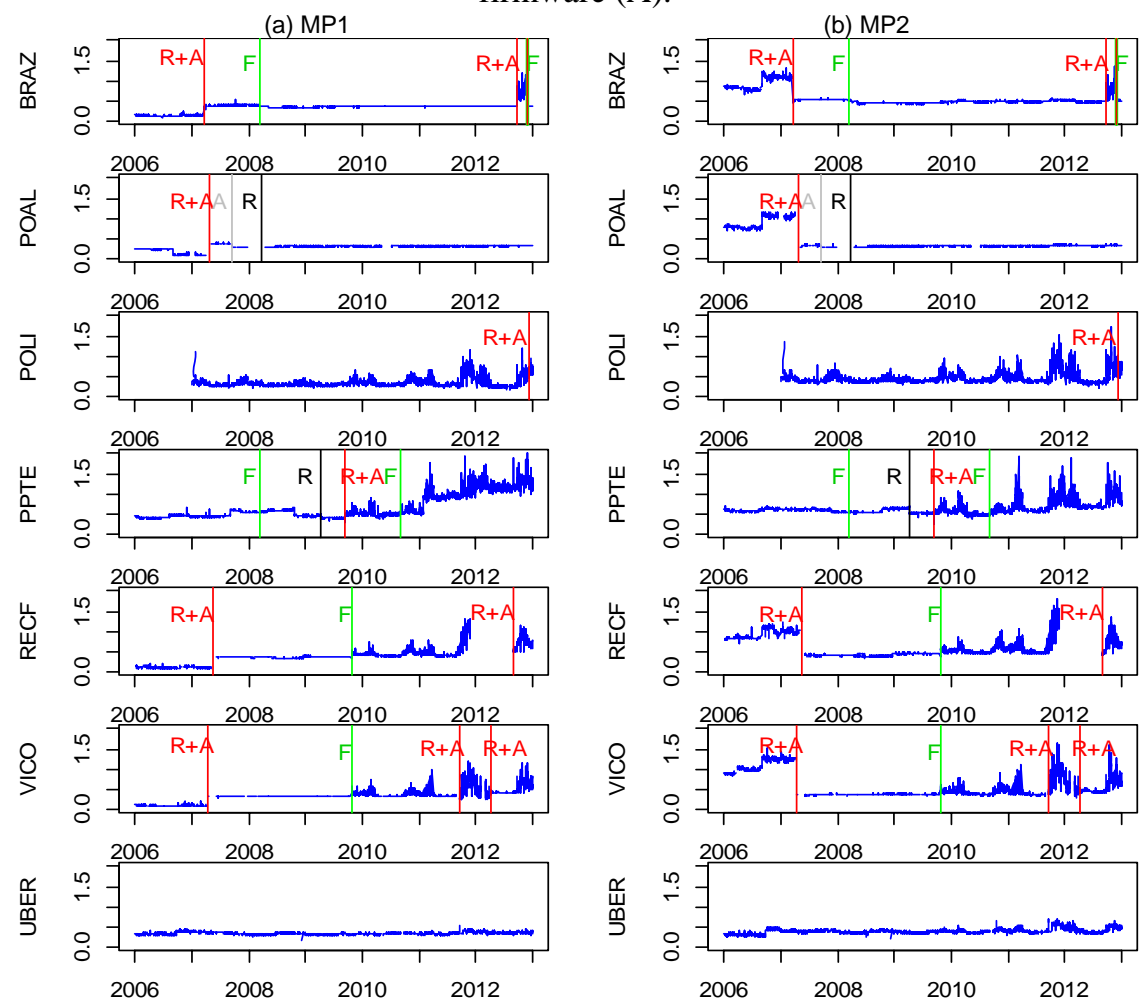

Figura 03 - Série temporal de MP1 da estação BRAZ no ano de 2012.

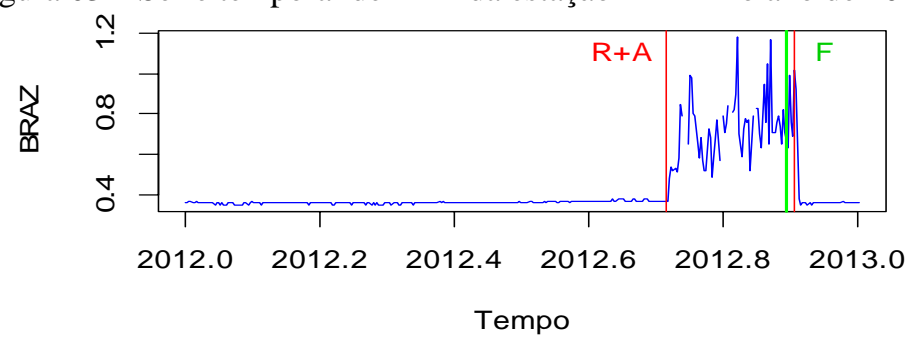

Bol. Ciênc. Geod., sec. Artigos, Curitiba, v. 19, nº 3, p.353-373, jul-set, 2013. 
Algo que também fica nítido na Figura 02 é como a atualização de firmware interfere no nível de ruído dos dados. Isso fica claro nas estações RECF e VICO. Note que, ao contrário do esperado, após a atualização de firmware os valores de MP1 e MP2 ficaram muito mais instáveis para ambas estações. Já em outro caso, como por exemplo BRAZ, a atualização de firmware não trouxe mudanças na série temporal.

A magnitude dos valores de MP1 e MP2 também são bastante diferentes nas estações, a Figura 04 traz os valores em conjunto para uma análise mais detalhada.

Figura 04 - Série temporal de MP1 e MP2 para estações da RBMC.
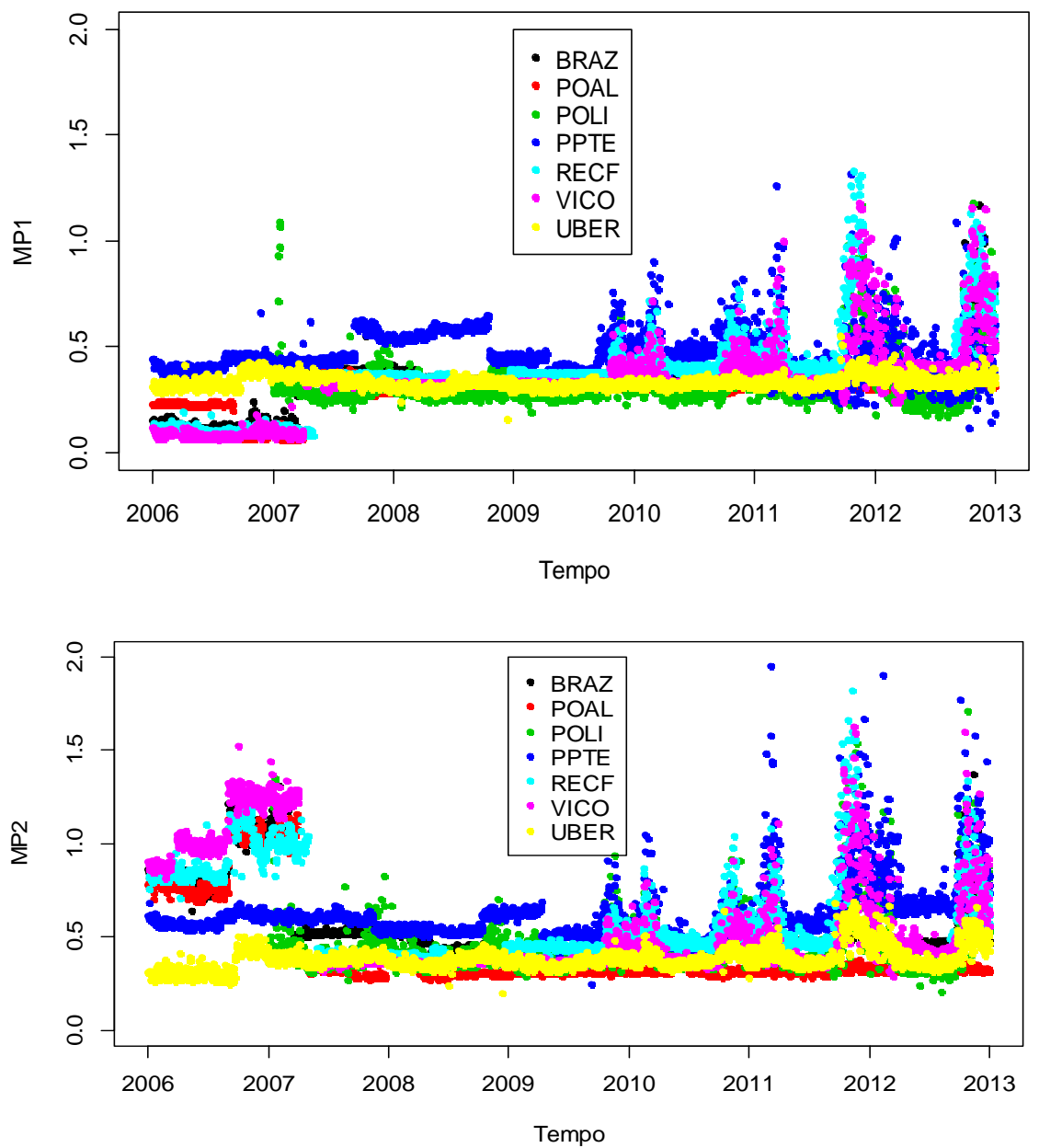

Bol. Ciênc. Geod., sec. Artigos, Curitiba, v. 19, nº 3, p.353-373, jul-set, 2013. 
Na Figura 4 percebe-se que a magnitude do MP1 e MP2 se aproxima de 2m, principalmente para a estação PPTE, que possui os maiores valores. A estação com os menores valores, principalmente para MP2, é a estação POAL que se mantém com valores em torno de $0,35 \mathrm{~m}$. Em documento da UNAVCO (http://facility.unavco.org/science_tech/dev_test/publications/ari_test.pdf) são apresentados resultados de um grande número de experimentos para obtenção de valores de MP para diversos receptores, para MP1 os valores ficaram entre 0,17 e 0,51 m. Já para MP2 foram obtidos valores entre 0,17 m e aproximadamente 1,1 m. Em contrapartida, Vasquez e Grejner-Brzeziska (2011) realizaram análises relativas ao efeito do multicaminho para uma rede de estações na Antártida e foram obtidos valores de até $1 \mathrm{~m}$ para MP1 e $3 \mathrm{~m}$ para MP2. Mas, nessa situação, as estações estavam próximas a rochas, painéis solares e refletores, que são fontes em potencial para o efeito do multicaminho.

Algo que também é notório nas séries temporais das Figuras 02 e 04 é a variabilidade dos valores de MP. Como se tratam de estações de referência, a expectativa é que essas séries permanecessem estáveis no decorrer do tempo, devido a repetibilidade do multicaminho. Mas, o que se vê (Figuras 2 e 4), é que esse comportamento aparentemente estável só ocorre para as estações BRAZ e POAL. Nas demais estações é possível verificar dois picos por ano, que ocorrem geralmente em março e outubro. Além disso, a magnitude desses picos está aumentando no final da série temporal. Para avaliar a existência dessa aparente sazonalidade e tendência em algumas séries temporais foram estimados correlogramas, modelos lineares e harmônicos, bem como periodogramas, conforme apresentados na seção 4. Os resultados são apresentados nas próximas seções.

\subsection{Análise de Sazonalidade}

Para investigar a sazonalidade em séries temporais, foram primeiramente estimados os correlogramas das séries temporais. Conforme discutido na seção 4, para a correta estimação e interpretação do correlograma, as séries devem ser estacionárias. Desse modo, os correlogramas foram calculados para os períodos das séries sem mudanças abruptas de nível (devido a alguma troca de receptor, por exemplo). Apenas no caso de PPTE, foram feitas correções na mudança de nível e também de tendência para o cálculo do periodograma no período posterior a setembro de 2009 (Figura 5).

Nota-se na Figura 5 que após as transformações, foi eliminada a mudança no nível médio e a tendência, mas continuam evidentes as mudanças na variância da série ao longo do tempo, principalmente nos finais e inícios do anos. Embora essas mudanças prejudiquem a estimativa do periodograma, não inviabilizam sua interpretação. 
Figura 05 - Série temporal original de MP1 da estação PPTE de setembro de 2009 a dezembro de 2012 e suas respectivas correções de mudança de nível e tendência, ambos estimados a partir de um modelo de regressão linear.

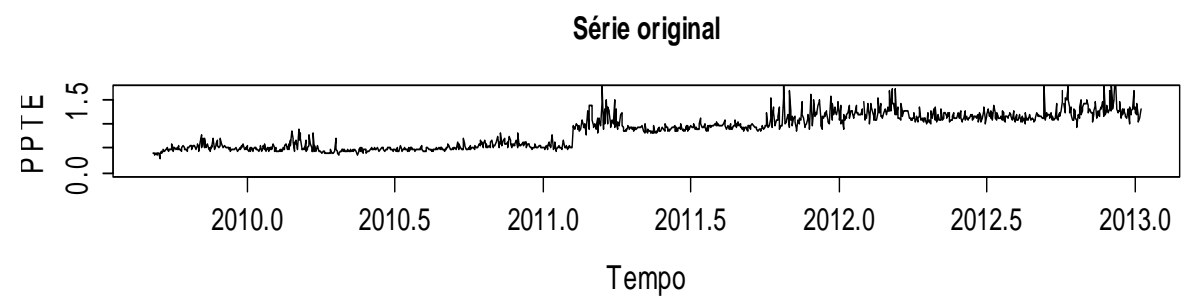

Correção da mudança de nível

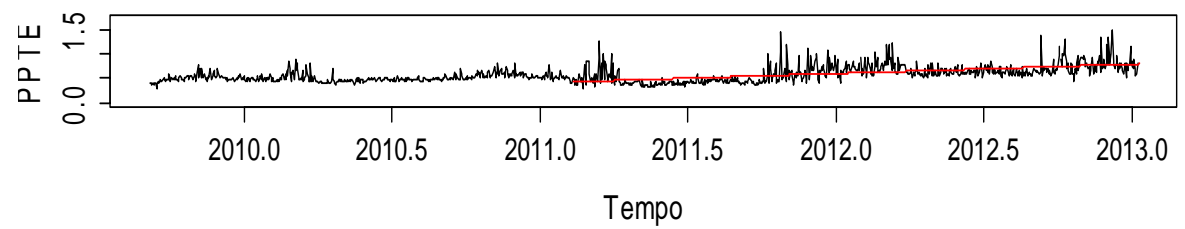

Correção da mudança de nível e tendência

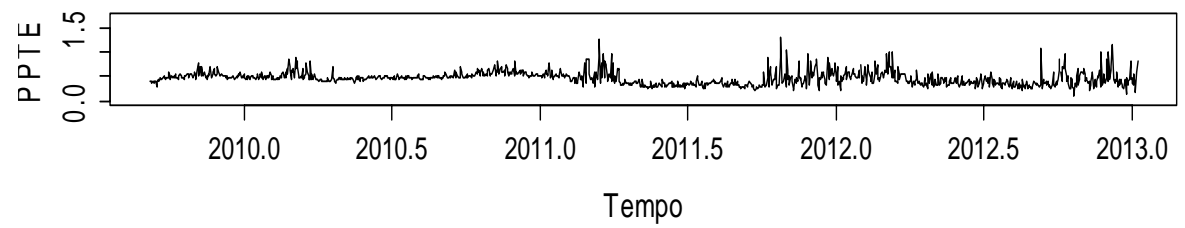
MP2.

Na Figura 6 são plotados os correlogramas para as séries temporais de MP1 e

Conforme apresentado na seção 4, as oscilações cíclicas no correlograma com autocorrelações fora do intervalo de confiança (linhas tracejadas azuis) nas proximidades da defasagem 12 meses (em vermelho na Figura 05) indicam a presença de sazonalidade. Na Figura 06, nota-se que as séries de MP1 para braz e uber não apresentaram autocorrelações significativas nas proximidades da defasagem 12. Para MP1 em POAL, essa autocorrelação parece transladada. Tal fato pode ocorrer devido aos dados faltantes ao longo da série. 
Figura 06 - Correlogramas das séries temporais de MP1 e MP2.
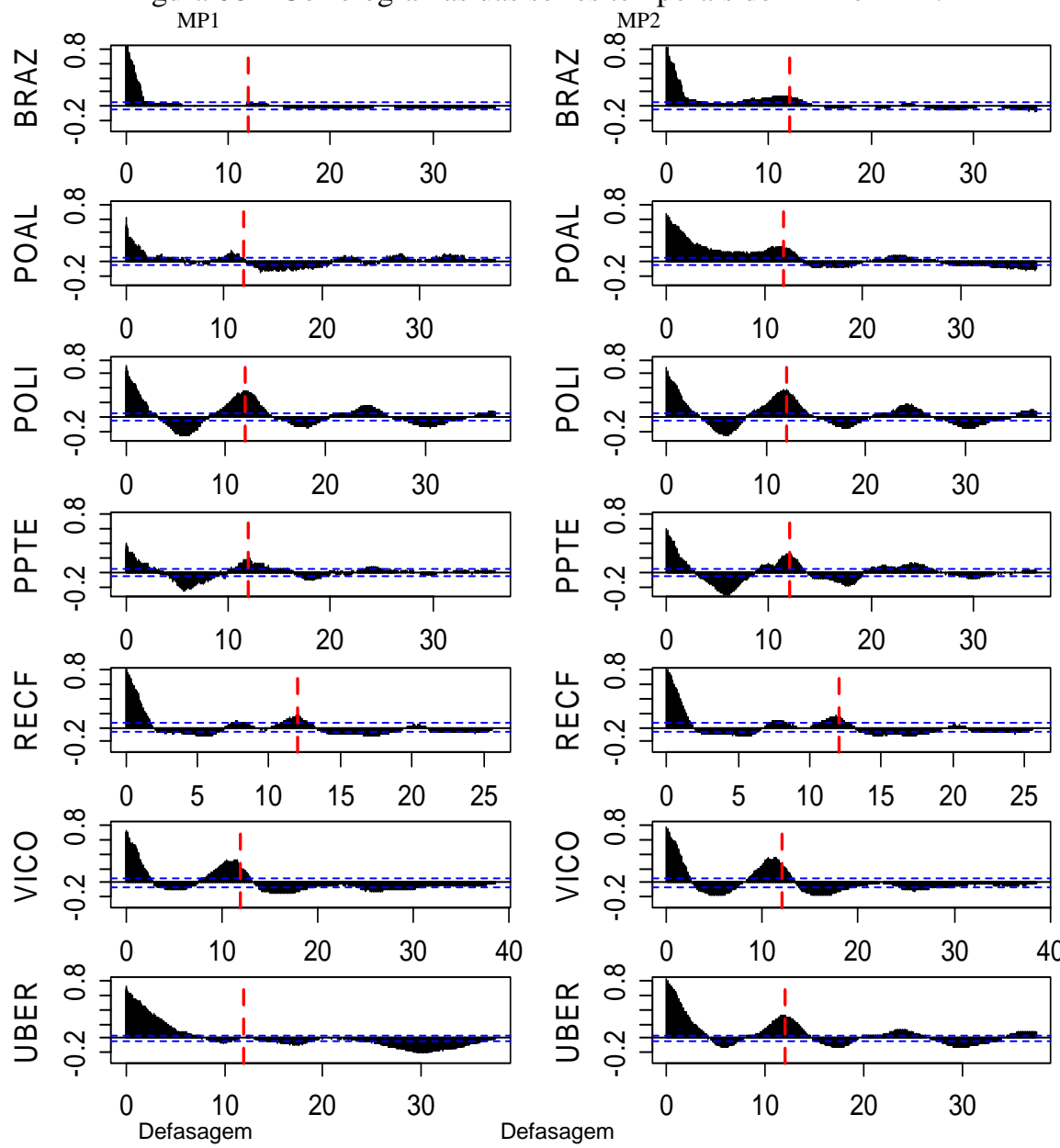

Para confirmar tais sazonalidades, as quais se referem à presença de efeitos que estão se repetindo em períodos de 12 meses, foram plotados os periodogramas de Fourier na Figura 7.

Na Figura 7, pode-se notar um pico em azul na frequência 0,002734375, o que representa uma periodicidade de 365 dias (= 1/0.002734375). A linha vermelha está indicando exatamente essa periodicidade, a qual coincide com a estimada (em azul) para todas as estações. Assim, mesmo quando a sazonalidade não ficou clara nos correlogramas (Figura 5), pode-se confirma-la pelos periodogramas de Fourier. 
Embora a presença de sazonalidade tenha sido confirmada, ainda é necessário identificar seu comportamento, indicando as épocas em que seu efeito é mais expressivo. Nesse sentido, a modelagem harmônica de Fourier apresentada na seção 4.1 é bastante útil.

Figura 07 - Periodogramas de Fourier para as séries temporais de MP1 e MP2.
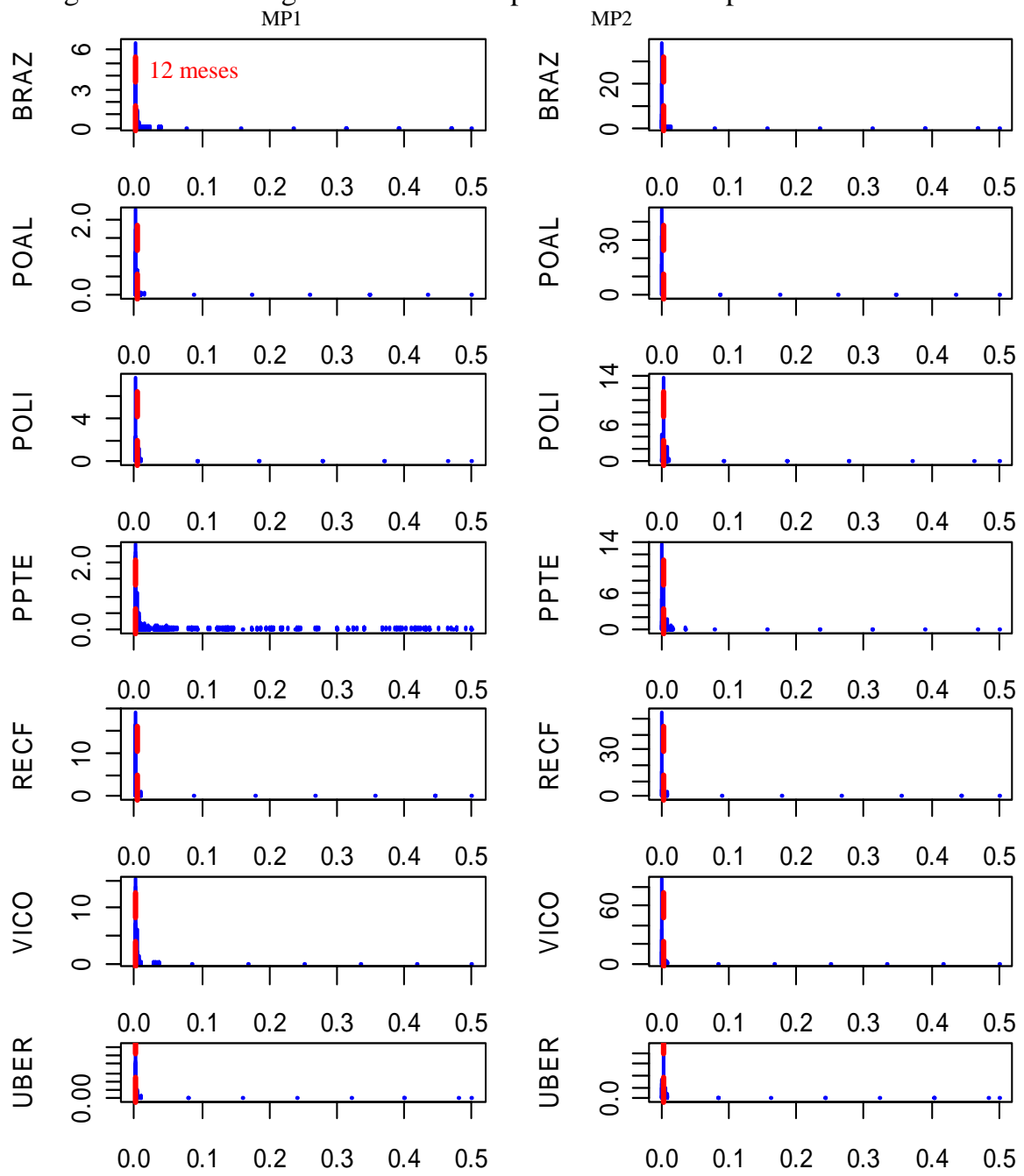

Nas Figuras 8 e 9 são ilustrados os respectivos ajustes para as séries de MP1 para as estações POLI e PPTE (com correção do nível médio e tendência) para os períodos em que a sazonalidade está bem nítida.

Bol. Ciênc. Geod., sec. Artigos, Curitiba, v. 19, nº 3, p.353-373, jul-set, 2013. 
Nas Figuras 08 e 09, apesar da grande variabilidade das séries temporais e heterocedasticidade (variância não constante ao longo do tempo), verifica-se que a modelagem harmônica foi capaz de detectar os picos próximos de outubro e março.

Figura 08 - Série temporal de MP1 para POLI e respectivo ajuste harmônico.

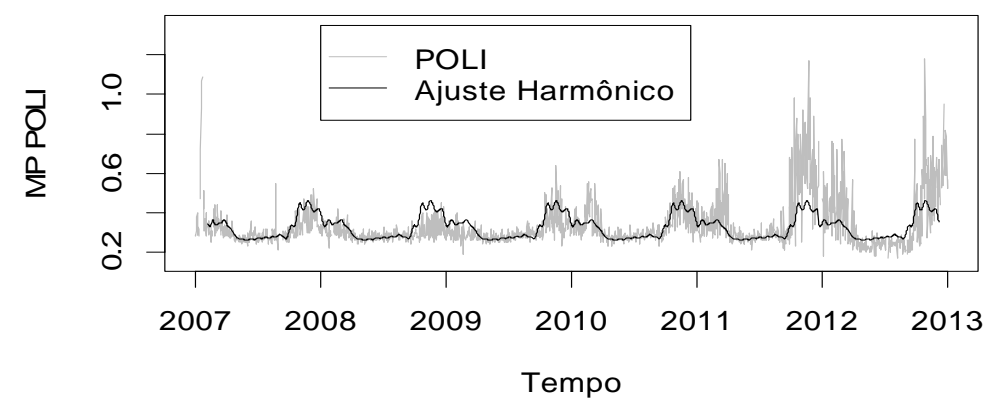

Figura 09 - Série temporal de MP1 para PPTE e respectivo ajuste harmônico.

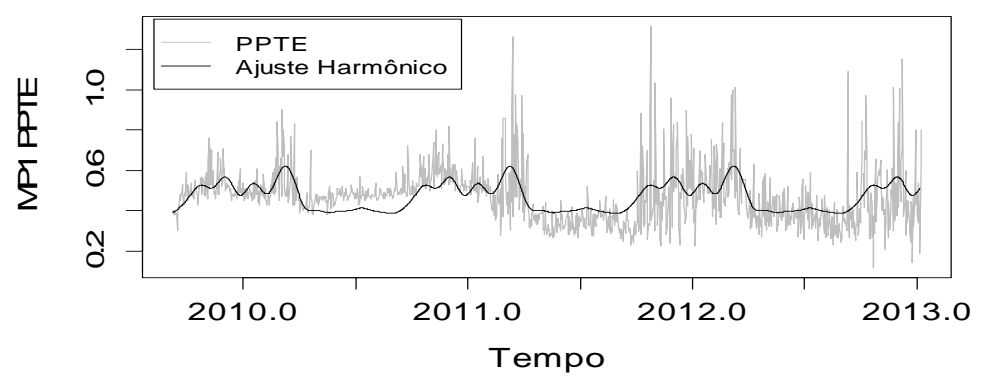

Nas Figuras 10, 11 e 12, são apresentadas as mesmas análises para MP1 em BRAZ, POAL e UBER.

Figura 10 - Série temporal MP1 para BRAZ e respectivo ajuste harmônico.

(a)

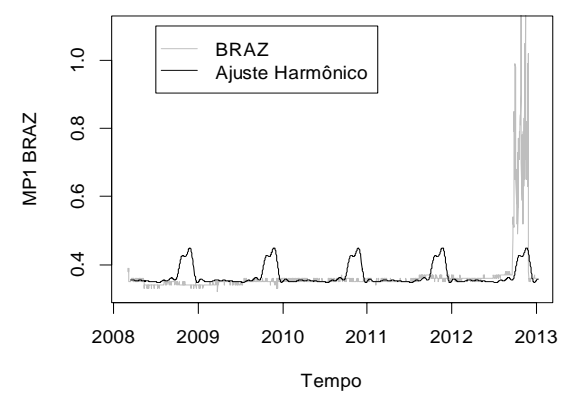

(b)

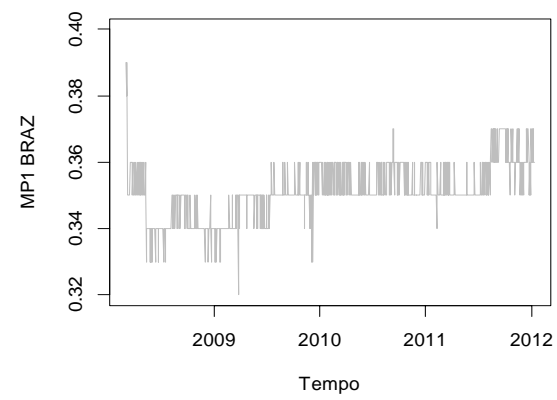

Bol. Ciênc. Geod., sec. Artigos, Curitiba, v. 19, no3, p.353-373, jul-set, 2013. 
Nota-se na Figura 10(a) que a sazonalidade anteriormente indicada no periodograma (Figura 7) se deve principalmente aos efeitos de maior magnitude no fim 2012, que ocorreram devido à troca de receptor e antena (detalhado na Figura 03). Esses efeitos "puxam" o ajuste de forma que a amplitude dos ciclos no período 2008-2011 seja bem mais evidenciada que a série observada, mas de maneira que acomode parte dos efeitos no fim 2011 e 2012. Ao analisar essa série excluindo o ano de 2012 (Figura 10b), verifica-se que não é possível identificar sazonalidades e nem estimar um modelo harmônico estatisticamente significativo.

Figura 11 - Série temporal MP1 para POAL e respectivo ajuste harmônico.

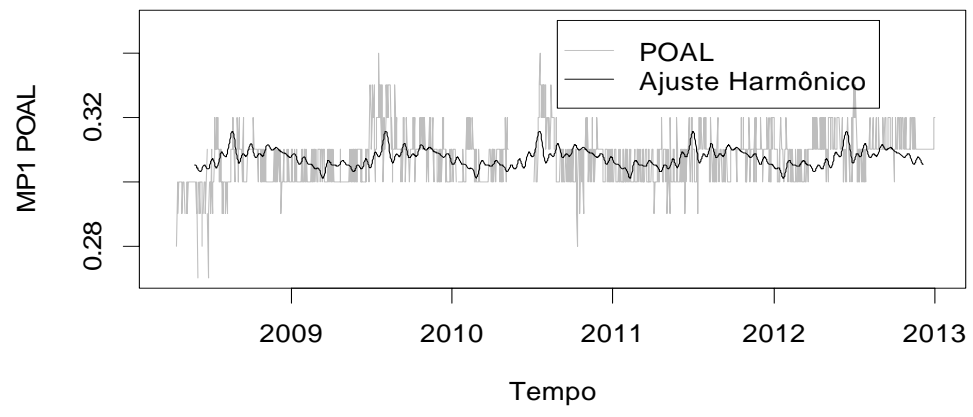

Nota-se na Figura 11, que embora tenha sido ajustado um modelo harmônico, trata-se de uma modelagem difícil para observar sazonalidade, pois são efeitos de baixa magnitude e muito próximos do próprio ruído da série.

Figura 12 - Série temporal MP1 para UBER e respectivo ajuste harmônico.

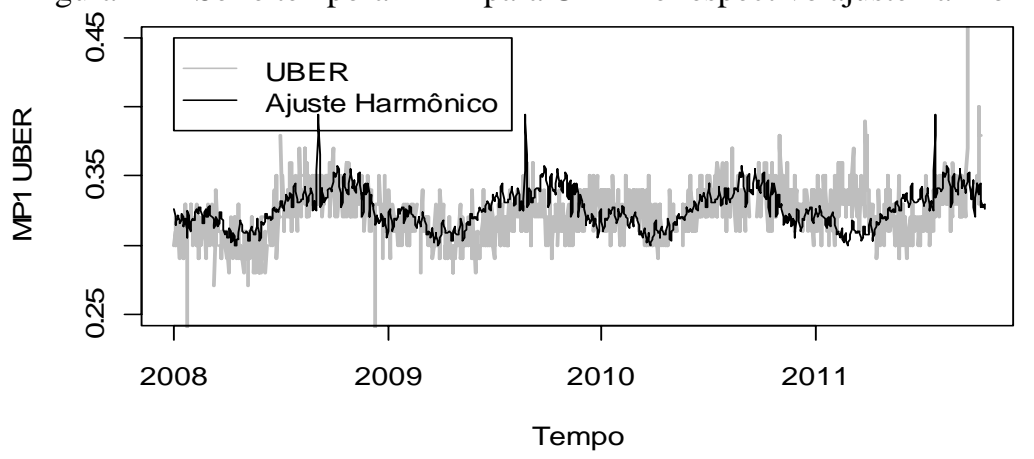

$\mathrm{Na}$ Figura 12, pode-se observar que mesmo os efeitos sendo de baixa magnitude, o ajuste harmônico conseguiu identificar os picos em outubro. Em março de 2009, os valores ajustados estão próximos dos observados, entretanto, 
para março de 2010 e 2011, o efeito foi subestimado, uma vez que os valores observados são bem mais expressivos.

Os respectivos ajustes harmônicos para MP2 também confirmam as análises apresentadas. Conforme pode ser visualizado na Figura 2, o efeito sazonal em março e outubro para MP2 é muito claro, o que faz com que os ajustes harmônicos para MP2 sejam melhores que para MP1, não sendo, portanto, necessário apresenta-los.

Em todos os ajustes harmônicos apresentados, foram verificados e mantidos os componentes estatisticamente significativos no modelo.

\subsubsection{Possível Causa da Sazonalidade}

Para estações de referência, o esperado é que o efeito do multicaminho se mantenha estável no decorrer do tempo, como apresentado na maior parte da série temporal da estação POAL (Figura 02). Mas, o índice MP, como discutido na seção 3.1, traz informações sobre a qualidade dos dados. A partir das equações (1) e (2) fica claro que se o valor do MP muda bruscamente, isso pode significar um efeito acentuado de multicaminho na $P D$ ou a ocorrência de perda de ciclos.

$\mathrm{O}$ que se viu nas séries temporais foi um efeito sazonal acentuado para a maior parte das estações, principalmente para aquelas situadas na região do Equador Geomagnético. A partir das análises estatísticas realizadas foi possível perceber valores maiores de MP em outubro seguido por valores de intensidade pouco menor em março, ocasionando dois picos anuais nas séries. Além disso, os menores valores de MP se concentram nos meses de junho e julho.

Essa característica anual das séries apresenta alta correlação com o efeito ionosférico, em especial a cintilação ionosférica. Efeito esse que pode ocasionar perdas de ciclos, e consequentemente afetar os índices MP1 e MP2. A Figura 13 apresenta o índice de cintilação S4 para o ano de 2012. Nessa figura é possível ver claramente os picos que ocorrem aproximadamente em março e outubro, assim como nos índices de multicaminho.

Figura 13 - Índice S4 de cintilação ionosférica do ano de 2012 para a estação PRU1 localizada em Presidente Prudente próxima a estação PPTE.

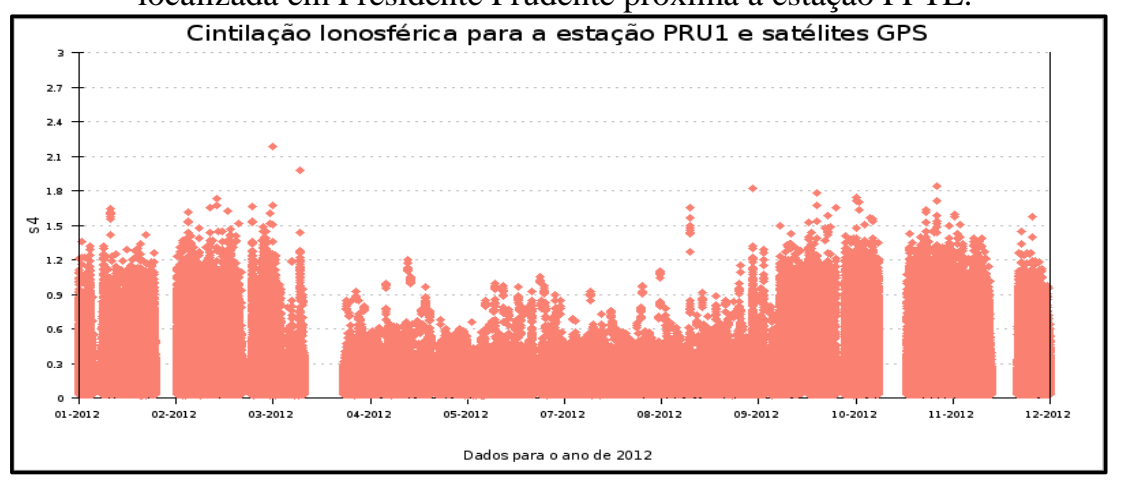

Bol. Ciênc. Geod., sec. Artigos, Curitiba, v. 19, no3, p.353-373, jul-set, 2013. 


\section{CONSIDERAÇÕES FINAIS}

O posicionamento realizado empregando dados de estações de monitoramento contínuo, tanto para o método relativo ou baseado em redes, tem sido muito empregado nos últimos anos. Com o objetivo de avaliar a qualidade dos dados dessas estações, foram geradas e avaliadas nesse artigo dados de séries temporais de MP1 e MP2 para algumas estações da RBMC.

Com as análises realizadas para as Figuras 02, 03 e 04 foi possível perceber que diferentes estações possuem magnitudes bastante distintas. Uma das causas dessa diferença se deve ao tipo de equipamento (antena/receptor) empregado. Na Figura 03 ficou nítido como uma troca do conjunto receptor/antena pode influenciar no ruído apresentado pela observável através dos índices de MP. Além disso, estranhamente, a atualização de firmware, em muitos casos, tem influenciado de forma negativa os índices de MP, que apresentam um aumento após esse evento. Situação ocorrida nas estações RECF e VICO no ano de 2009.

Realizadas especulações iniciais com as séries temporais foi possível notar sazonalidade em algumas estações. Para avaliar esse fenômeno de forma mais efetiva foram aplicados os modelos harmônicos, correlogramas e periodogramas aos dados das séries. Nas Figuras de 05 a 07 ficou clara essa sazonalidade para grande parte das estações. Mas ainda restaram dúvidas a respeito de algumas estações, como por exemplo, POAL. Para sanar essas dúvidas, foi aplicado o ajuste harmônico, onde foi possível verificar que realmente algumas estações (caso de POAL - Figura 11) não apresentam claramente tal sazonalidade. Além disso, através do ajuste harmônico foi possível identificar picos em março e outubro.

Investigações também foram realizadas no intuito de identificar o motivo dessa sazonalidade. Como os índices de MP são altamente correlacionados com perda de ciclos, e se sabe que os efeitos da ionosfera, em especial da cintilação ionosférica, podem ocasionar essas perdas, essa sazonalidade, provavelmente se deve a tal efeito. A Figura 12 trouxe o comportamento dos índices de cintilação de uma estação localizada no equador geomagnético, e nota-se claramente alta correlação com o efeito do MP para as estações da RBMC, principalmente aquelas localizadas na região do equador geomagnético, como por exemplo, PPTE. Finalizando, é nítido nessas séries que os valores dos índices estão aumentando, o que reforça ainda mais essa conclusão, visto que em 2013 deve ocorrer o pico da atividade solar, aumentando ainda mais os efeitos da ionosfera nos sinais GNSS.

\section{AGRADECIMENTOS}

A primeira autora gostaria de agradecer ao $\mathrm{CNPq}$ (bolsa PQ e projeto universal - processo 470112/2012-3) e à FAPESP (projeto regular - processo 2012/19906-7) pelo apoio financeiro à pesquisa. A segunda autora também agradece ao $\mathrm{CNPq}$ (bolsa PQ Processo 304247/2012-0). 


\section{REFERÊNCIAS BIBLIOGRÁFICAS}

ALVES, D. B. M. Posicionamento Baseado em redes GPS utilizando o conceito de estação virtual, 2008. Tese (Doutorado em Ciências Cartográficas) Universidade Estadual Paulista, Presidente Prudente.

ALVES, D. B. M.; MONICO, J. F. G. GPS/VRS positioning using atmospheric modeling. GPS Solutions (Heidelberg), v.15, p. 253-261, 2011.

CHATFIELD, C. The Analysis of Times Series: An Introduction. Chapman and Hall: London, 1995.

CONKER; R. S.; EL-ARINI, M. B.; HEGARTY, C. J.; HSIAO, T. Modeling the Effects of Ionospheric Scintillation on GPS/Satellite-Based Augmentation System Availability. Radio Science, v. 38, 2003.

CRYER, J.D.; CHAN, K.S. Time Series Analysis: With Applications in R, Springer Texts in Statistics, 2008.

ESTEY, L.H.; MEERTENS, C.M. TEQC: The multi-purpose toolkit for GPS/GLONASS Data. GPS Solutions, v. 3, n. 1, p. 42-49, 1999.

FORTES, L.P.S. Operacionalização da rede brasileira de monitoramento contínuo do sistema GPS (RBMC). 1997. 152 f. Dissertação (Mestrado em Ciências em Sistemas e Computação) - Instituto Militar de Engenharia (IME), Rio de Janeiro.

Hilla S.; Cline M. Evaluating Pseudorange Multipath Effects at Stations in the National CORS Network. In: Weiko A. Heiskanen Symposium in Geodesy, Ohio State University, Columbus, Ohio. Proceedings... 2002.

LEICK, A. GPS - Satellite Surveying. 2.ed. John Wiley \& Sons, 1995. 560p.

MORETTIN, P. A.; TOLOI, C. M. C. Análise de Séries Temporais. Edgar Blucher: São Paulo, 2004.

RAY, J. Systematic errors in GPS position estimates. In: IGS Workshop 2006. Proceedings... 2006.

R CORE TEAM, R: A Language and Environment for Statistical Computing. R Foundation for Statistical Computing, Vienna, Áustria, 2012 Disponível em: $<$, http://www.R-project.org >. Acesso em: 21 mar. 2013.

SEEBER, G. Satellite Geodesy: Foundations, Methods, and Applications. Berlin, New York: Walter de Gruyter, 2003.

SOUZA, E. M. Análise de Wavelets para Detecção e Correção do Multicaminho no Posicionamento Relativo GNSS Estático e Cinemático, 2008. Tese (Doutorado em Ciências Cartográficas) - Universidade Estadual Paulista, Presidente Prudente.

UNAVCO (2010). TEQC - Tutorial. Disponível em: <http://www.unavco.org/ facility/software/teqc/tutorial.html>. Acesso em: 04 mar. 2013.

VÁZQUEZ B. G. E.; GREJNER-BRZEZISKA, D. A. A case of study for Pseudorange multipath estimation and analysis: TAMDEF GPS network. Geofísica Internacional, v. 51, n.1, p. 63-72, 2012.

(Recebido em abril de 2013. Aceito em junho de 2013) 